\title{
Cooperative Glutamatergic and Cholinergic Mechanisms Generate Short-Term Modifications of Synaptic Effectiveness in Prepositus Hypoglossi Neurons
}

\author{
Juan de Dios Navarro-López, ${ }^{1}$ José M. Delgado-García, ${ }^{2}$ and Javier Yajeya ${ }^{3}$ \\ ${ }^{1}$ Centro Regional de Investigaciones Biomédicas, Universidad de Castilla-La Mancha, 02071 Albacete, Spain, ${ }^{2}$ División de Neurociencias, Universidad Pablo \\ de Olavide, 41013 Sevilla, Spain, and ${ }^{3}$ Instituto de Neurociencias de Castilla y León, Universidad de Salamanca, 37007 Salamanca, Spain
}

\begin{abstract}
To maintain horizontal eye position on a visual target after a saccade, extraocular motoneurons need a persistent (tonic) neural activity, called "eye-position signal," generated by prepositus hypoglossi $(\mathrm{PH})$ neurons. We have shown previously in vitro and in vivo that this neural activity depends, among others mechanisms, on the interplay of glutamatergic transmission and cholinergic synaptically triggered depolarization. Here, we used rat sagittal brainstem slices, including PH nucleus and paramedian pontine reticular formation (PPRF). We made intracellular recordings of PH neurons and studied their synaptic activation from PPRF neurons. Train stimulation of the PPRF area evoked a cholinergic-sustained depolarization of PH neurons that outlasted the stimulus. EPSPs evoked in PH neurons by single pulses applied to the PPRF presented a short-term potentiation (STP) after train stimulation. APV (an NMDA-receptor blocker) or chelerythrine (a protein kinase-C inhibitor) had no effect on the sustained depolarization, but they did block the evoked STP, whereas pirenzepine (an $\mathrm{M}_{1}$ muscarinic antagonist) blocked both the sustained depolarization and the STP of PH neurons. Thus, electrical stimulation of the PPRF area activates both glutamatergic and cholinergic axons terminating in the PH nucleus, the latter producing a sustained depolarization probably involved in the genesis of the persistent neural activity required for eye fixation. $\mathrm{M}_{1}$-receptor activation seems to evoke a STP of PH neurons via NMDA receptors. Such STP could be needed for the stabilization of the neural network involved in the generation of position signals necessary for eye fixation after a saccade.
\end{abstract}

Key words: acetylcholine; glutamate; short-term potentiation; prepositus hypoglossi; oculomotor system; rats

\section{Introduction}

It has been shown in both cats and monkeys that neurons located in the prepositus hypoglossi $(\mathrm{PH})$ nucleus encode pure eye position and functionally related position-velocity and velocity-position signals (Delgado-García et al., 1989; Fukushima et al., 1992; McFarland and Fuchs, 1992; Moschovakis, 1997). Indeed, transient pharmacological inactivations or permanent electrolytic lesions of the $\mathrm{PH}$ nucleus indicate that prepositus neural circuits are necessary for the generation of eye position signals subsequent to on- and off-directed saccades (Cheron and Godaux, 1987; Arnold et al., 1999; Moreno-López et al., 2002). $\mathrm{PH}$ neurons receive eye velocity signals from excitatory burst neurons (EBN) located in the paramedian pontine reticular formation (PPRF) (Igusa et al., 1980), and they project monosynaptically on extraocular motoneurons and other brainstem and cerebellar structures related to eye movements (McCrea and Baker, 1985). As a result, it has been suggested that $\mathrm{PH}$ neurons perform the neural integration of eye velocity signals into eye position

Received May 22, 2005; revised Sept. 11, 2005; accepted Sept. 12, 2005.

This work was supported by grants from Junta de Andalucía (CVI-122) and Dirección General de Investigación Científica y Técnica (BFI2002-00936). We thank R. Churchill for his editorial help.

Correspondence should be addressed to Prof. José M. Delgado-García, División de Neurociencias, Universidad Pablo de Olavide, Carretera de Utrera, kilómetro 1, 41013 Sevilla, Spain. E-mail: jmdelgar@dex.upo.es. DOI:10.1523/JNEUROSCI.2061-05.2005

Copyright $\odot 2005$ Society for Neuroscience $\quad$ 0270-6474/05/259902-05\$15.00/0 motor commands in the horizontal plane (Robinson, 1981; Delgado-García et al., 1989; Moschovakis, 1997).

It has been shown recently that the sustained activity present in $\mathrm{PH}$ neurons during eye fixations is the result, at least partially, of synaptic events evoked by EBN, located in the PPRF, and cholinergic neurons, located either in the pontomesencephalic region and/or in the PH nucleus (Navarro-López et al., 2004). These synaptic effects were mediated by AMPA-kainate and $M_{1}$ muscarinic receptors located in $\mathrm{PH}$ neurons. Here, we show that train stimulation of the PPRF (mimicking eye velocity signals) evokes a short-term potentiation (STP) that follows the sustained activity of PH neurons. In this case, the activation of NMDA receptors (NMDAR) and $M_{1}$ muscarinic receptors is apparently responsible for the short-lasting potentiation of $\mathrm{PH}$ neurons. We also provide evidence that the interplay between NMDA and $M_{1}$ receptors seems to be mediated intracellularly through intermediate steps including the activation of protein kinase $C$ (PKC) (Salter and Kalia, 2004). Thus, more than one synaptic mechanism seems to be involved in the generation of eye position signals characterizing the firing of $\mathrm{PH}$ neurons.

\section{Materials and Methods}

Animals. Experiments were performed in 25-35 rats (50-75 g) raised in the Salamanca University Animal House. Experiments were performed according to the European Union directive (609/86/EU) for the use of laboratory animals in acute experiments. 
Preparation of slices. Animals were anesthetized deeply with halothane gas and decapitated. The brain was excised and immersed rapidly in oxygenated ice-cold $\left(4-6^{\circ} \mathrm{C}\right)$ artificial CSF (ACSF) with sucrose $(234$ $\mathrm{mm}$ ) replacing the $\mathrm{NaCl}(117 \mathrm{~mm})$ to maintain osmolarity. Brainstem sagittal slices (350 $\mu \mathrm{m}$ thick) were cut in cold oxygenated Ringer's solution using a Vibratome-S1000 (Technical Products International, O'Fallon, MO) and placed in an incubation chamber, where they were maintained for $\sim 2 \mathrm{~h}$ at room temperature. Additional details of this in vitro preparation have been described previously (Yajeya et al., 2000).

In vitro recordings. For recordings, a single slice containing $\mathrm{PH}$ nucleus and rostral PPRF was transferred to an interface recording chamber (BSC-HT and BSC-BU; Harvard Apparatus, Holliston, MA) and perfused continuously with ACSF comprising the following (in $\mathrm{mM}$ ): 117 $\mathrm{NaCl}, 4.7 \mathrm{KCl}, 2.5 \mathrm{CaCl}_{2}, 1.2 \mathrm{MgCl}_{2}, 25 \mathrm{NaHCO}_{3}, 1.2 \mathrm{NaH}_{2} \mathrm{PO}_{4}$, and 11 glucose. The ACSF was bubbled with carbogen gas $\left(95 \% \mathrm{O}_{2}-5 \% \mathrm{CO}_{2}\right)$ and maintained at $30 \pm 2^{\circ} \mathrm{C}$.

Intracellular records from $\mathrm{PH}$ neurons were obtained with borosilicate glass microelectrodes (140-180 M $\Omega$; World Precision Instruments, Sarasota, FL) filled with a potassium acetate solution $(3 \mathrm{M})$ and connected to the head stage of an intracellular recording amplifier (VF180; Biologic, Claix, France). Micropipette tips were directed to the rostral third of the $\mathrm{PH}$ nucleus, where neurons carrying eye position signals are located (Delgado-García et al., 1989; Navarro-López et al., 2004). Only data from neurons that had stable resting potential with absolute values greater than $-60 \mathrm{mV}$ in the absence of DC holding currents and that presented overshooting action potentials were collected for analysis. Spike amplitude and afterhyperpolarizing potentials were measured relative to threshold.

Synaptic potentials were elicited orthodromically by stimulating the ipsilateral PPRF using a monopolar stainless-steel electrode (2 M $\Omega$ of effective resistance; World Precision Instruments) and a programmable stimulator (Master-8; AMPI, Jerusalem, Israel). Single, cathodal, squarewave pulses of $100-200 \mu$ s duration and $100-500 \mu \mathrm{A}$ intensity were adjusted to subthreshold values for orthodromic spike generation. Postsynaptic potentials were characterized according to their amplitude (as a function of the resting potential) and latency. When needed, the same stimulating pulses were also presented in trains (100 $\mathrm{ms})$ at $50-200 \mathrm{~Hz}$.

Identification of stimulating and recording sites. Recorded neurons were identified following procedures described previously (Navarro-López et al., 2004). Briefly, selected neurons were stained by the intracellular injection of biocytin diluted in a $2 \mathrm{~m}$ potassium acetate solution (McDonald, 1992) using positive current pulses of $0.2 \mathrm{nA}$ for $6 \mathrm{~min}$. Slices were fixed and cut in sections $(45 \mu \mathrm{m})$ using a freezing microtome (HM400R; Microm, Heidelberg, Germany). Sections were incubated with avidin-biotin-peroxidase complex (Vector Laboratories, Burlingame, CA). 3,3'-Diaminobenzidine was used as chromogen for visualization of the biocytin complex. Alternate sections were counterstained with cresyl violet. Neurons were reconstructed from serial sections using a camera lucida (Nikon Labophot; Nikon, Kawasaki, Japan).

Drugs. All chemicals used in this study were applied by superfusion in the ACSF. The chemicals used were atropine sulfate (a nonspecific antagonist of cholinergic receptors), 6-cyano-nitroquinoxaline-2,3-dione (CNQX; a potent, competitive AMPA-kainate receptor antagonist), and 2-amino-5-phosphonovalerate (APV; a specific blocker of NMDAR) from Sigma (St. Louis, MO), pirenzepine (a selective blocker of $\mathrm{M}_{1}$ muscarinic receptors) from Biogen Científica (Madrid, Spain), and chelerythrine chloride (specific and potent, cell-permeable inhibitor of PKC) from Alomone Labs (Jerusalem, Israel).

Data storage and statistical analysis. Data were acquired and stored, as analog signal, on a videocassette, using a modified video recorder (Physiorec-3; Cibertec, Madrid, Spain). Off-line data acquisition and analysis were performed with the help of a Cambridge Electronic Design (Cambridge, UK) 1401 interface between the tape recorder and a computer, using the Mini Analysis program, version 5.2.1 (Synaptosoft, Decatur, GA). Unless otherwise indicated, the electrophysiological data are always expressed as mean $\pm \mathrm{SEM}$, and $n$ represents the number of averaged neurons. Synaptic potentials were averaged $(\geq 5)$ before quantitative analysis. Statistical analysis of collected data was performed using a
A

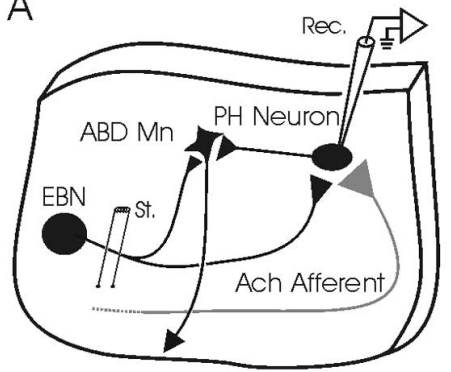

C

B
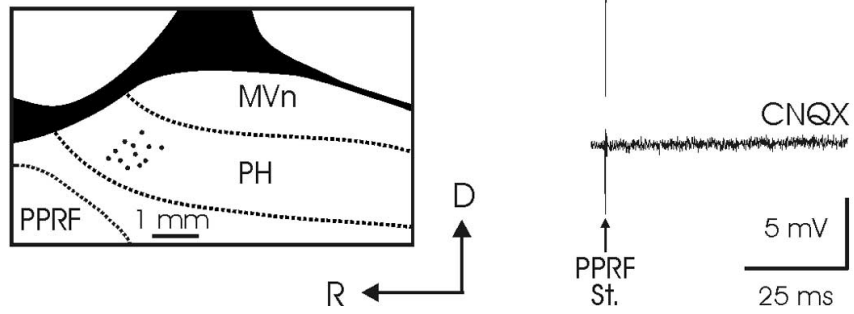

Figure 1. Neural circuits and connectivity. $A$, A diagram illustrating neural circuits present in the sagittal brainstem slice used here. EBN are located in the PPRF, rostrally to abducens nucleus motoneurons (ABD Mn), and project monosynaptically on PH neurons. Stimuli (St.) applied to the PPRF also activate cholinergic neurons and/or axons. Rec., Recording electrode. $\boldsymbol{B}$, Location of some ( $n=12)$ biocytin-injected neurons to illustrate the recording area. R, Rostral; D, dorsal; MVn, medial vestibular nucleus. C, Glutamatergic nature of PPRF synaptic contacts on PH neurons. Top, EPSP evoked in a PH neuron by a single subthreshold stimulus (St.; $100 \mu \mathrm{s}, 200 \mu \mathrm{A}$ ) applied to the PPRF. The EPSP was not affected by atropine sulfate (1 $\mu \mathrm{M})$ or APV $(50 \mu \mathrm{m})$, but the application of CNQX (10 $\mu \mathrm{M})$ completely removed the evoked synaptic potential.

paired Student's $t$ test and, when necessary, one-way ANOVA. Statistical significance was determined at a level of $p \leq 0.05$.

\section{Results}

\section{Characterization of $\mathrm{PH}$ neurons and their response to} PPRF stimulation

This study comprises 42 intracellular recordings from $\mathrm{PH}$, selected because of their resting potential (less than or equal to -60 $\mathrm{mV}$ ) and monosynaptic activation from the PPRF. PH neurons were identified electrophysiologically by the absence of spontaneous firing at resting membrane potential and the presence of a biphasic afterhyperpolarization in their action potential when depolarized (Navarro-López et al., 2004). The location of selected PH neurons $(n=12)$ filled with biocytin is illustrated in Figure $1 B$. The morphology and initial axonal trajectories of labeled $\mathrm{PH}$ neurons suggest that they could be considered "principal cells" (McCrea and Baker, 1985) (i.e., a type of $\mathrm{PH}$ cell projecting to many brainstem sites related to the oculomotor system, including the abducens nucleus).

Single subthreshold stimulations of the PPRF evoked monosynaptic EPSPs in PH neurons in all cases $(n=42)$. The EPSPs presented a mean latency of $2.57 \pm 0.30 \mathrm{~ms}$, a rise time of $6.5 \pm$ $2.9 \mathrm{~ms}$, a decay time of $20.8 \pm 8.7 \mathrm{~ms}$, and a duration of $71.6 \pm$ $23.8 \mathrm{~ms}$ (Fig. 1C, top). EPSPs evoked in PH neurons by PPRF stimulation were not modified in amplitude or latency by slice superfusion with atropine sulfate $(1-3 \mu \mathrm{M})$ or APV $(50 \mu \mathrm{M})$ but were removed completely by the application of CNQX (10-12 $\mu \mathrm{M}$ ) (Fig. 1C). These results indicate that the EPSP evoked in $\mathrm{PH}$ neurons by PPRF stimulation was mediated by glutamate acting exclusively on AMPA-kainate receptors, at least when stimulus rate was set at $\leq 0.2 \mathrm{~Hz}$. 

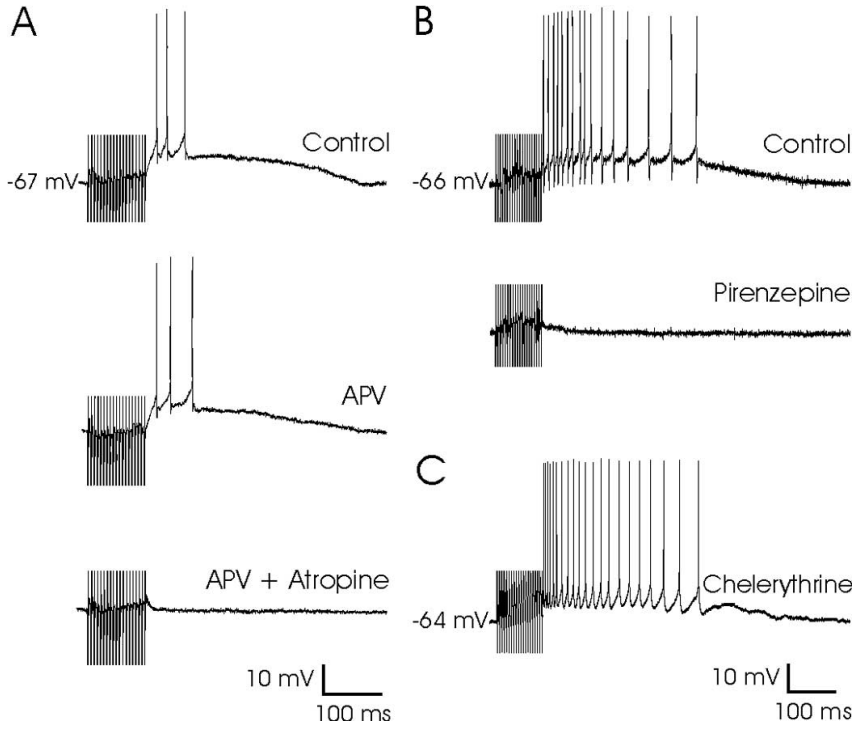

Figure 2. Differential effects of train stimulation of PPRF on PH neurons in presence of glutamatergic and/or cholinergic drugs. $A$, The top record (Control) illustrates the effect of a PPRF train $(100 \mathrm{~ms}, 200 \mathrm{~Hz}, 200 \mu \mathrm{A})$ on a PH cell. Note the large and sustained depolarization recorded after the end of the train. The middle record shows that the application of APV (50 $\mu \mathrm{M})$ to the bathing solution did not affect the posttrain activation of the $\mathrm{PH}$ neuron. In contrast, this sustained depolarization of the $\mathrm{PH}$ neuron was impossible to evoke in the presence of atropine sulfate $(1 \mu \mathrm{M})$. B, Top, Another example of sustained depolarization, including a lasting burst of action potentials, evoked in a PH neuron by train stimulation $(100 \mathrm{~ms}, 200 \mathrm{~Hz}, 450 \mu \mathrm{A})$ of the PPRF. Superfusion with pirenzepine (bottom; $0.5 \mu \mathrm{M}$ ) completely removed the evoked posttrain depolarization. $C$, The sustained depolarization of $\mathrm{PH}$ neurons after train stimulation (100 $\mathrm{ms}, 200 \mathrm{~Hz}, 425 \mu \mathrm{A})$ of the PPRF was not affected by chelerythrine $(2.5 \mu \mathrm{M})$. The resting membrane potential for the illustrated neurons is indicated. Calibration in $\mathbf{C}$ also applies to $\boldsymbol{B}$.
A

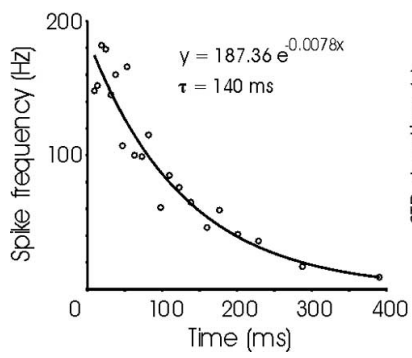

B

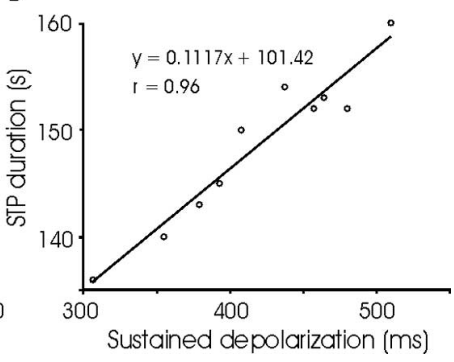

Figure 3. Plots of $\mathrm{PH}$ neuron responses after train stimulation. $\boldsymbol{A}$, Exponential decay of burst firing evoked in PH neurons after train stimulation of PPRF. The illustrated data correspond to a single recording collected from a PH neuron. The burst of action potentials was evoked after a train of stimuli $(100 \mathrm{~ms}, 200 \mathrm{~Hz}, 400 \mu \mathrm{A})$ applied to the PPRF $(r=0.979 ; p<0.01)$. B, Plot of STP duration (in seconds) against sustained cholinergic depolarization duration (in milliseconds). Each point corresponds to the responses of one neuron $(n=10)$.

\section{Differential effects of train stimulation of PPRF on $\mathrm{PH}$ neurons in presence of glutamatergic and/or cholinergic drugs}

Train stimulation $(200 \mathrm{~Hz}, 100 \mathrm{~ms})$ of the PPRF evoked a sustained depolarization of $\mathrm{PH}$ neurons that exceeded the end of the train by up to $400-500 \mathrm{~ms}$ (Fig. 2). This persisting depolarization was large enough to evoke a burst of action potentials that reached peak frequencies of 150-200 spikes/s. The frequency of the burst of action potentials evoked by PPRF train stimulation decayed with time, with a time constant of $140 \pm 15 \mathrm{~ms}$ (range, $70-210 ; n=11 ; p<0.01$ ) (Fig. 3A) [i.e., a value similar to the time constants of cat abducens motoneurons (90-197 ms) (Delgado-García et al., 1986) and "position-velocity" PH neu-
A

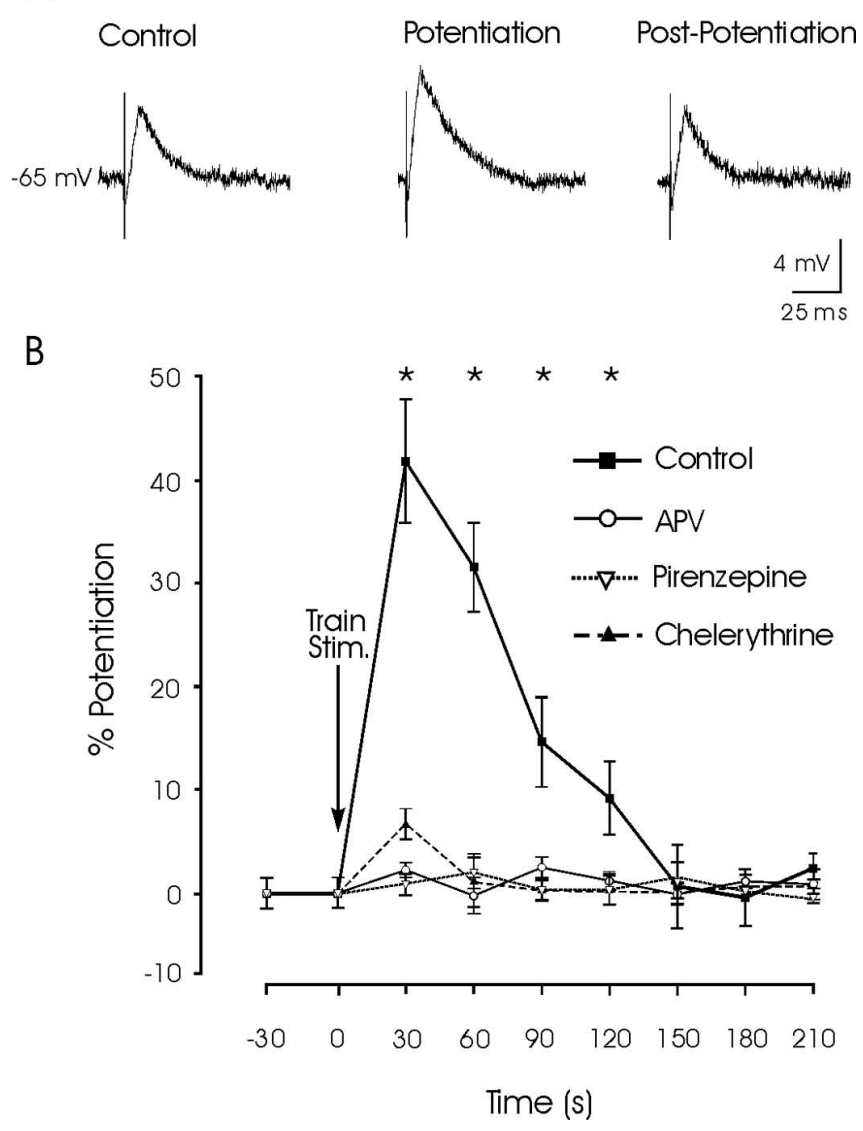

Figure 4. STP of PH neurons after train stimulation of PPRF. A, EPSPs evoked in a PH neuron by single subthreshold stimuli applied to the PPRF $30 \mathrm{~s}$ before (Control), and $30 \mathrm{~s}$ (Potentiation) and $180 \mathrm{~s}$ (Post-Potentiation) after train stimulation $(100 \mathrm{~ms}, 200 \mathrm{~Hz}, 250 \mu \mathrm{A}$; arrow) of PPRF. $B$, Quantitative analysis of the synaptic potentiation evoked in PH neurons $(n=15)$ by a train of stimuli (Train Stim.) presented to the ipsilateral PPRF. Potentiation was determined as the percentage increase in the amplitude of the evoked EPSP. Data represent mean percentage \pm $S D$, computed every $30 \mathrm{~s}$. Note that the STP was present at significant values (asterisks) for $\sim 120 \mathrm{~s}(p \leq 0.01)$. Single pulses applied to the PPRF were presented at a rate of $0.2 \mathrm{~Hz}$. STP was not evoked in the presence of APV (50 $\mu \mathrm{m} ; n=8)$, pirenzepine $(0.5 \mu \mathrm{m} ; n=6)$, or chelerythrine $(2.5 \mu \mathrm{m} ; n=5)$ superfused to the bathing solution.

rons recorded in behaving cats (46-371 ms) (Delgado-García et al., 1989)].

The sustained depolarization was the probable result of $\mathrm{M}_{1}$ muscarinic-receptor activation, because the effect was removed by atropine sulfate ( $1 \mu \mathrm{M} ; n=7)$ (Fig. $2 A)$ and by pirenzepine $(0.5 \mu \mathrm{M} ; n=6)$ (Fig. $2 B$ ). However, superfusion with APV (50 $\mu \mathrm{M} ; n=8)$ or chelerythrine (2.5 $\mu \mathrm{M} ; n=6)$ had no effect on sustained depolarization or on action potentials firing (Fig. $2 \mathrm{~A}$, $C$, respectively). Thus, the monosynaptic effects of PPRF on $\mathrm{PH}$ were mediated by the activation of AMPA-kainate receptors, whereas the sustained depolarization was caused by the activation of M1 cholinergic receptors.

\section{STP of PH neurons after train stimulation of PPRF}

Train stimulation of the PPRF also produced an STP of EPSPs evoked in $\mathrm{PH}$ neurons by single pulses presented to that reticular formation zone. We compared the amplitude of EPSPs evoked in PH neurons $(n=15)$ by single pulses applied to the PPRF before and after the application of a train of stimuli $(200 \mathrm{~Hz}, 100 \mathrm{~ms}$, 200-300 $\mu \mathrm{A}$ ) to the same PPRF area (Fig. 4A). Data are represented as the percentage increase with respect to control EPSPs, 
using the following equation: potentiation percentage $=[($ experimental EPSP amplitude/control EPSP amplitude) - 1] $\times 100$. Compared with control values, the train of stimuli produced a significant $(p \leq 0.01)$ increase in EPSP amplitude lasting for $120 \mathrm{~s}$, reaching a maximum increase $(41.7 \pm 6.0 \% ; p<0.001)$ $30 \mathrm{~s}$ after the train (Fig. $4 \mathrm{~B}$ ). The potentiation decreased exponentially with time, with a time constant of $79.8 \pm 9.2 \mathrm{~s}$. Durations of the sustained depolarization (Fig. 2) and that of the STP (Fig. 4) were related linearly $(p<0.01)$ (Fig. $3 B$ ). Bath superfusion with APV (50 $\mu \mathrm{M} ; n=8)$ completely removed the EPSP potentiation evoked in $\mathrm{PH}$ neurons by train stimulation of the PPRF (Fig. $4 B$ ), suggesting an NMDA dependence. Blocking the sustained depolarization with pirenzepine $(0.5 \mu \mathrm{M} ; n=6)$ or atropine sulfate $(1 \mu \mathrm{M} ; n=7)$ (data not shown) also blocked the STP. Such results sustained the interdependence of NMDA and $\mathrm{M}_{1}$ muscarinic receptors. Finally, chelerythrine $(2.5 \mu \mathrm{M} ; n=5)$ also blocked the STP, which means that it is mediated by the activation of PKC.

\section{Discussion}

\section{Interaction between muscarinic and glutamatergic receptors} located in PH neurons

It is known that train stimulation $(>30 \mathrm{~Hz})$ is able to activate cholinergic axons (Moises et al., 1995; Faber and Sah, 2002) and that cholinergic axons originated in the pontomesencephalic reticular formation projects to the $\mathrm{PH}$ nucleus (Carpenter et al., 1987; Semba et al., 1990). It can therefore be suggested that cholinergic axons projecting onto $\mathrm{PH}$ neurons were activated during train stimulation of the PPRF (Navarro-López et al., 2004). However, it is also possible that cholinergic neurons located in $\mathrm{PH}$ (Tighilet and Lacour, 1998) are activated by collateral axons of the ipsilateral and contralateral circuits involved in the integration of eye position signals from eye velocity motor commands (Aksay et al., 2003). The presence of an $M_{1}$ muscarinic cholinergic modulation of glutamatergic (NMDA) synapses has been studied at the striatum (Calabresi et al., 1998) and the hippocampus (Marino et al., 1998; Fernández de Sevilla et al., 2002; Sur et al., 2003). The activation of G-protein-coupled receptors, such as the $M_{1}$ muscarinic receptor, potentiates NMDA-evoked responses in hippocampal neurons (Marino et al., 1998; Sur et al., 2003). This potentiation is blocked by pharmacological inhibition of endogenous PKC (Lu et al., 1999). In its turn, PKC seems to enhance NMDAR-mediated synaptic currents in neurons ( $\mathrm{Lu}$ et al., 1999; Salter and Kalia, 2004). As shown here for PH neurons, the activation of $\mathrm{M}_{1}$ receptor enhances NMDAR-mediated synaptic currents via PKC.

The presence of positive and negative feedbacks in premotor extraocular circuits, particularly those generating eye position signals, have been suggested (Escudero et al., 1992; Aksay et al., 2003). The level of synchronization between neurons present in those circuits could give some information regarding the stability of the neuronal integrator (Tegnér et al., 2002; Aksay et al., 2003). It has been shown that the ratio between synaptic currents generated by NMDA versus AMPA receptors plays an important role in the generation of the persistent activity necessary for eye fixation (Tegnér et al., 2002). Thus, when the ratio is large, the degree of synchronization in the neural integrator circuit is low, and network stability is increased (Aksay et al., 2003). As experimental support for these theoretical contentions, the two mechanisms proposed here (sustained depolarization and STP), involving AMPA-kainate and NMDA glutamatergic receptors, are dependent on the coincident activation of $\mathrm{M}_{1}$ muscarinic receptors, as further indicated by their linear relationship (Fig. 3B).

\section{Persistent activity and STP are both present in $\mathrm{PH}$ neurons}

As proposed recently (Navarro-López et al., 2004) and confirmed here, train stimulation of the PPRF, with stimulus parameters similar to those evoked in PPRF neurons during normal saccades in behaving mammals, is able to produce a sustained depolarization of $\mathrm{PH}$ neurons outlasting the train by up to $500 \mathrm{~ms}$. This sustained depolarization is dependent both on the activation of AMPA-kainate receptors by EBN (Igusa et al., 1980) and on cholinergic axons terminating on the same $\mathrm{PH}$ neurons and acting on $\mathrm{M}_{1}$ muscarinic receptors. These results, collected from brainstem slices, have been confirmed in behaving cats by the local (at the $\mathrm{PH}$ nucleus) injection of different cholinergic drugs (NavarroLópez et al., 2004). Here, we also report an STP (lasting for $\sim 120$ s) evoked in $\mathrm{PH}$ neurons by train stimulation of the PPRF. In this case, the potentiation seems to be mediated by NMDAR, because it was easily blocked by superfusion with APV, indicating a postsynaptic origin. Additional proof that this STP has a postsynaptic origin is that both pirenzepine and chelerythrine were able to block it when applied to the bathing solution.

Although the sustained depolarization triggered in $\mathrm{PH}$ neurons by PPRF stimulation (i.e., by EBN) (Igusa et al., 1980) carrying eye velocity signals can be described as a synaptic mechanism involved in the generation of the neural persisting activity (Aksay et al., 2003; Major and Tank, 2004; Navarro-López et al., 2004) necessary for eye positions of fixation, the role of the STP described here is of a difficult interpretation within oculomotor system performance. The involvement of NMDAR of the $\mathrm{PH}$ in the generation of eye position signals has been demonstrated previously in the alert cat (Cheron et al., 1992; Mettens et al., 1994). On the basis of in vivo and in vitro experiments, the NMDA-related STP mechanism seems to be crucial for persistent activity in the PH. This is somewhat paradoxical, because STP, mainly in the form of posttetanic potentiation, was first described in motor networks, although, in recent years, it has been related more with cortical network functioning (Nadim and Manor, 2000). Nevertheless, the reported STP could act as a mechanism for high-pass filtering in oculomotor function, facilitating the synchronous activation of (postsynaptic) PH neurons, increasing signal-to-noise ratio (Lisman, 1997), and canceling out the disturbing effects of low rate firing of EBN. STP could still be useful in facilitating the action of error signals addressed to correct aimed versus achieved eye positions (Schultz and Dickinson, 2000). In this regard, Shen (1989) proposed a model of oculomotor integration based on potentiation phenomena at the synaptic level. If we assume an opposite action (i.e., short-term depression) evoked by contralateral inhibitory burst neurons (Hikosaka et al., 1980), the in vivo interplay of short-term synaptic facilitation and depression would help network stability and maintenance (Nadim and Manor, 2000). In contrast, the sustained activity that follows train stimulation of the PPRF seems to be related more with the generation of eye position signals. Indeed, the amplitude and duration of the evoked EPSPs are related linearly to train frequency (Navarro-López et al., 2004), and, as shown here, the time constant of the decaying firing (Fig. $3 A$ ) is similar to the time constant of $\mathrm{PH}$ and abducens neurons and of the oculomotor plant (Robinson, 1981; Delgado-García et al., 1989; Fukushima et al., 1992; Moschovakis, 1997).

\section{References}

Aksay E, Baker R, Seung HS, Tank DW (2003) Correlated discharge among cell pairs within the oculomotor horizontal velocity-to-position integrator. J Neurosci 23:10852-10858.

Arnold DB, Robinson DA, Leigh RJ (1999) Nystagmus induced by pharma- 
cological inactivation of the brainstem ocular motor integrator in monkey. Vision Res 39:4286-4295.

Calabresi P, Centonze D, Gubellini P, Pisani A, Bernardi G (1998) Endogenous Ach enhances striatal NMDA-responses via M1-like muscarinic receptors and PKC activation. Eur J Neurosci 10:2887-2895.

Carpenter MB, Chang L, Pereira AB, Hersh LB (1987) Comparisons of the immunocytochemical localization of choline acetyltransferase in the vestibular nuclei of the monkey and rat. Brain Res 418:403-408.

Cheron G, Godaux E (1987) Disabling of the oculomotor neuronal integrator by kainic acid injections in the prepositus-vestibular complex in the cat. J Physiol (Lond) 399:267-290.

Cheron G, Mettens P, Godaux E (1992) Gaze holding defect induced by injections of ketamine in the cat brainstem. NeuroReport 3:97-100.

Delgado-García JM, del Pozo F, Baker R (1986) Behav of neurons in the abducens nucleus of the alert cat-I. Motoneurons. Neuroscience 4:929-952.

Delgado-García JM, Vidal P-P, Gómez C, Berthoz A (1989) A neurophysiological study of prepositus hypoglossi neurons projecting to oculomotor and preoculomotor nuclei in the alert cat. Neuroscience 29:291-307.

Escudero M, de la Cruz RR, Delgado-Garcia JM (1992) A physiological study of vestibular and prepositus hypoglossi neurones projecting to the abducens nucleus in the alert cat. J Physiol (Lond) 458:539-560.

Faber ESL, Sah P (2002) Physiological role of calcium-activated potassium currents in the rat lateral amygdala. J Neurosci 22:1618-1628.

Fernández de Sevilla D, Cabezas C, Oshima de Prada AN, Sánchez-Jiménez A, Buño W (2002) Selective muscarinic regulation of functional glutamatergic Schaffer collateral synapses in rat CA1 pyramidal neurons. J Physiol (Lond) 545:51-63.

Fukushima K, Kaneko CRS, Fuchs AF (1992) The neuronal substrate of integration in the oculomotor system. Prog Neurobiol 39:609-639.

Hikosaka O, Igusa Y, Imai H (1980) Inhibitory connections of nystagmusrelated reticular burst neurons with neurons in the abducens prepositus hypoglossi and vestibular nucleus in the cat. Exp Brain Res 39:301-311.

Igusa Y, Sasaki S, Shimazu H (1980) Excitatory premotor burst neurons in the cat pontine reticular formation related to the quick phase of vestibular nystagmus. Brain Res 182:451-456.

Lisman JE (1997) Burst as a unit of neuronal information: making unreliable synapses reliable. Trends Neurosci 20:38-43.

Lu WY, Xiong ZG, Lei S, Orser BA, Dudek E, Browning MD, MacDonald JF (1999) G-protein-coupled receptors act via protein kinase C and Src to regulate NMDA receptors. Nat Neurosci 2:331-338.

Major G, Tank D (2004) Persistent neural activity: prevalence and mechanisms. Curr Opin Neurobiol 14:675-684.

Marino MJ, Rouse ST, Levey Ai, Potter LT, Conn PJ (1998) Activation of the genetically defined ml muscarinic receptor potentiates $\mathrm{N}$-methyl-Daspartate (NMDA) receptor currents in hippocampal pyramidal cells. Proc Natl Acad Sci USA 95:11465-11470.

McCrea R, Baker R (1985) Anatomical connections of the nucleus prepositus of the cat. J Comp Neurol 237:377-407.
McDonald AJ (1992) Neuroanatomical labeling with biocytin: a review. NeuroReport 3:821-827.

McFarland JL, Fuchs AF (1992) Discharge patterns in nucleus prepositus hypoglossi and adjacent medial vestibular nucleus during horizontal eye movement in behaving macaques. J Neurophysiol 68:319-332.

Mettens P, Cheron G, Godaux E (1994) NMDA receptors are involved in temporal integration in the oculomotor system of the cat. NeuroReport 5:1333-1336.

Moises HC, Womble MD, Washburn MS, Williams LR (1995) Nerve growth factor facilitates cholinergic neurotransmission between nucleus basalis and the amygdala in the rat: an electrophysiological analysis. J Neurosci 15:8131-8142.

Moreno-López B, Escudero M, Estrada C (2002) Nitric oxide facilitates GABAergic neurotransmission in the cat oculomotor system: a physiological mechanism in eye movement control. J Physiol (Lond) 540:295-306.

Moschovakis AK (1997) The neuronal integrators of the mammalian saccadic system. Front Biosci 15:D552-D577.

Nadim F, Manor Y (2000) The role of short-term synaptic dynamics in motor control. Curr Opin Neurobiol 10:683-690.

Navarro-López JD, Alvarado JC, Márquez-Ruiz J, Escudero M, DelgadoGarcía JM, Yajeya J (2004) A cholinergic synaptically triggered event participates in the generation of persistent activity necessary for eye fixation. J Neurosci 24:5109-5118.

Robinson DA (1981) The use of control system analysis in the neurophysiology of eye movements. Annu Rev Neurosci 4:463-503.

Salter MW, Kalia LV (2004) SRC kinases: a hub for NMDA receptor regulation. Nat Rev Neurosci 5:317-328.

Schultz W, Dickinson A (2000) Neuronal coding of prediction errors. Annu Rev Neurosci 23:473-500.

Semba K, Reiner PB, Fibiger HC (1990) Single cholinergic mesopontine tegmental neurons project to both the pontine reticular formation and the thalamus in the rat. Neuroscience 38:643-654.

Shen L (1989) Neural integration by short term potentiation. Biol Cybern 61:319-325.

Sur C, Mallorga PJ, Wittmann M, Jacobson MA, Pascarella D, Williams JB, Brandish PE, Pettibone DJ, Scolnick EM, Conn PJ (2003) $\mathrm{N}$-desmethylclozapine, an allosteric agonist at muscarinic 1 receptor, potentiates $N$-methyl-D-aspartate receptor activity. Proc Natl Acad Sci USA 100:13674-13679.

Tegnér J, Compte A, Wang X-J (2002) The dynamical stability of reverberatory neural circuits. Biol Cybern 87:471-481.

Tighilet B, Lacour M (1998) Distribution of choline acetyltransferase immunoreactivity in the vestibular nuclei of normal and unilateral vestibular neurectomized cats. Eur J Neurosci 10:3115-3126.

Yajeya J, de la Fuente A, Criado JM, Bajo V, Sánchez-Villalobos A, Heredia M (2000) Muscarinic agonistic carbachol depresses excitatory synaptic transmission in the rat basolateral amygdala in vitro. Synapse $38: 151-160$. 